\title{
Willard Bohn, Apollinaire on the Edge. Modern Art, Popular Culture, and the Avant-Garde
}

\section{Marianna Marino}

\section{OpenEdition}

\section{Journals}

\section{Edizione digitale}

URL: http://journals.openedition.org/studifrancesi/5743

DOI: $10.4000 /$ studifrancesi.5743

ISSN: 2421-5856

\section{Editore}

Rosenberg \& Sellier

\section{Edizione cartacea}

Data di pubblicazione: 1 septembre 2011

Paginazione: 450

ISSN: 0039-2944

\section{Notizia bibliografica digitale}

Marianna Marino, «Willard Bohn, Apollinaire on the Edge. Modern Art, Popular Culture, and the Avant-

Garde», Studi Francesi [Online], 164 (LV | II) | 2011, online dal 30 novembre 2015, consultato il 08 janvier 2021. URL: http://journals.openedition.org/studifrancesi/5743; DOI: https://doi.org/10.4000/ studifrancesi. 5743

Questo documento è stato generato automaticamente il 8 janvier 2021.

\section{(c) (i) ()}

Studi Francesi è distribuita con Licenza Creative Commons Attribuzione - Non commerciale - Non opere derivate 4.0 Internazionale. 


\title{
Willard Bohn, Apollinaire on the Edge. Modern Art, Popular Culture, and the Avant-Garde
}

\author{
Marianna Marino
}

\section{NOTIZIA}

WILLARD BOHN, Apollinaire on the Edge. Modern Art, Popular Culture, and the Avant-Garde, Amsterdam-New York, Rodopi, 2010 («Faux Titre», 355), 143 pp.

1 Le caratteristiche "intermedie" dell'opera di Guillaume Apollinaire sono messe in evidenza dalla presenza dell'edge-bordo, margine - nel titolo del volume. Ovvero, come recita l'elenco del sottotitolo, dalle relazioni che tale opera ha intessuto con l'arte moderna, la cultura popolare e l'avanguardia. In tal modo, osserva Willard Bohn, Apollinaire sarebbe riuscito a instaurare un delicato equilibrio tra senso e non-senso, tradizione e invenzione, ordine e avventura creativa.

2 Il volume si compone di quattro studi. Il primo (Contemplating "The Bestiary") è dedicato alla raccolta intitolata Le Bestiaire (pubblicata nel 1911) e al rapporto che i singoli componimenti poetici intrattengono con la resa visiva delle xilografie di Raoul Dufy. Si tratta di un'analisi testuale dettagliata della raccolta, in cui talvolta però le domande e le problematiche sembrano scarseggiare quanto a legittimità, col rischio frequente di cadere nel luogo comune.

3 Successivamente, il secondo capitolo (Apollinaire and the Whatnots) si concentra su Banalités, i cui testi apparvero tra il 1914 e il 1915 sulla rivista italiana «Lacerba» - il che offre lo spunto all'autore per accennare ai rapporti tra il poeta francese e i futuristi italiani. Anche in questo caso, l'analisi di Bohn è costituita soprattutto da serie ininterrotte di domande. Un tale atteggiamento interrogativo sembrerebbe il sintomo di un'ossessione che mira a scoprire il fattore scatenante della poesia: quello del critico 
si rivela spesso, così, uno sguardo medico-investigativo che purtroppo pare, a nostro modo di vedere, fallire la sua meticolosa autopsia.

4 A partire dal terzo studio (Apollinaire and the Children's Rhymes), l'analisi monografica cede il passo a uno sguardo più globale sull'opera del poeta, attraverso il rilevamento della presenza stilistica della filastrocca per bambini in varie poesie dell'autore. Un'attenzione particolare è riservata all'originale rappresentazione che il poeta offrì di una figura mitica del Simbolismo quale Salomé (in Vers et prose del 1905).

5 L'ultimo saggio si sofferma su Les Mamelles de Tirésias, di cui viene trascurato il valore seminale per il movimento surrealista a favore di una riflessione sulla lotta tra i sessi all'epoca della composizione del testo (prendendo in esame anche una presunta misoginia di Apollinaire). 